\title{
Quando Leis Não Produzem os Resultados Esperados: Financiamento Eleitoral em Perspectiva Comparada
}

\section{André Marenco}

Professor associado no Programa de Pós-Graduação em Ciência Política da Universidade Federal do Rio Grande do Sul (UFRGS). E-mail: amarenco@terra.com.br

- m que medida a legislação criada para controlar o financiamento

1 de campanhas eleitorais tem alcançado seu objetivo de ampliar o controle e, com isto, reduzir incentivos para a corrupção nas relações entre partidos, candidatos e fontes privadas de financiamento eleitoral? Diferentes modelos de legislação têm sido adotados por democracias para regular o financiamento de campanhas eleitorais: tetos máximos para contribuições, proibição de doações por empresas que prestam serviços ou concessões públicas, publicização de doações privadas e fundos públicos para cobrir gastos eleitorais (IDEA, 2009). A hipótese que orienta este trabalho sugere que não existe uma associação entre rigor na legislação e melhora nos indicadores de transparência institucional (Transparency International, 2009). As razões para isto devem ser localizadas nos custos elevados de monitoramento ininterrupto promovido pela legislação sobre financiamento eleitoral. Nesta perspectiva, resultados eficazes devem ser encontrados sob condições contextuais que favoreçam controles do tipo fire alarms (McCubbins e Schwartz, 1984).

O trabalho está organizado em quatro partes: na primeira, procurou-se destacar a importância adquirida pelo acesso ao financiamento eleitoral nas poliarquias contemporâneas; na sequência, foram apresentados os tipos de legislação destinada ao controle sobre financiamento eleitoral verificados em 84 casos nacionais; na terceira parte, é desen-

DADOS - Revista de Ciências Sociais, Rio de Janeiro, vol. 53, nº 4, 2010, pp. 821 a 853. 
volvida análise descritiva apresentando resultados discrepantes encontrados para a relação entre presença, tipo e detalhamento de legislação de financiamento eleitoral e indicadores de corrupção; na quarta parte buscou-se responder se os efeitos deste tipo de legislação poderiam ser potencializados pela combinação com configurações institucionais específicas: escalas de tempo de operação da legislação, democracia, presidencialismo, tipos de listas eleitorais e variações na magnitude das circunscrições eleitorais.

Foi desenvolvida análise inferencial com o emprego de regressão multivariada, buscando testar variáveis institucionais e econômicas para explicar as diferenças, em graus de corrupção, entre países que possuem legislação de financiamento eleitoral; finalmente, a conclusão sistematiza e analisa os resultados encontrados.

\section{DINHEIRO E CAMPANHAS ELEITORAIS EM POLIARQUIAS CONTEMPORÂNEAS}

O acesso a fontes de financiamento necessárias para dar suporte a campanhas eleitorais adquiriu lugar estratégico na competição partidária em poliarquias institucionalizadas. Dinheiro adquire importância na manutenção de máquinas partidárias e na conquista de votos em um contexto caracterizado pelo declínio ou ausência de partidos de massas, combinado aos custos crescentes de campanhas eleitorais, produto das mudanças técnicas geradas pela propaganda eleitoral nos meios de comunicação, instrumentos de sondagem de preferências e profissionalização de quadros e experts partidários.

Custos de campanhas eleitorais podem ser relativamente baixos, quando ideologias partidárias constituem instrumentos eficientes de economia de informação para o eleitor, produzindo votos partidários cativos e militância voluntária responsável pelo proselitismo partidário e por um padrão de arrecadação financeira do tipo grassroots, baseado na cotização de membros e simpatizantes (Bartolini, 2000). Mudanças nos padrões de organização partidária, provocadas por estratégias catch-all implicaram perda de importância de ideologias como elementos diferenciadores da oferta eleitoral e forte declínio no ativismo partidário voluntário (Mair e Van Biezen, 2001). Quando eleitores cativos e ativistas voluntários não estão mais disponíveis, estratégias para captação de votos implicam antecipar preferências de eleitores em potencial e conquistar votantes partidariamente não alinhados. $\mathrm{O}$ desen- 
volvimento técnico de sondagens de opinião pública, de recursos de propaganda eleitoral e da tecnologia dos meios de comunicação tornou-os indispensáveis a campanhas partidárias competitivas (Manin, 1995; Norris, 2000; de Vreese, 2009).

Tudo isto, entretanto, tem preço elevado, exponenciando custos de campanhas eleitorais. A escala e regularidade nos recursos financeiros necessários para sustentar campanhas competitivas vão muito além de um modelo tradicional de financiamento baseado em trabalho voluntário e contribuições individuais de filiados e quadros partidários. A campanha vitoriosa de Barack Obama teria arrecadado um total de U\$750 milhões, duas vezes mais do que doações e fundos públicos da campanha de McCain. Conforme dados da Transparência Brasil, o valor médio arrecadado por deputados federais eleitos para a Legislatura 2007/2010 da Câmara dos Deputados teria correspondido a $\mathrm{R} \$ 4,8$ por voto obtido. Este custo teria sido ainda mais elevado em colégios eleitorais de pequena magnitude, como Roraima ( $R$ \$ 11,1), Goiás ( $R$ \$ $8,8)$ ou Acre $(\mathrm{R} \$ 8,1)$.

O custo crescente de campanhas eleitorais e o acesso a fontes de financiamento privado contribuem para o reforço de ligaçães perigosas envolvendo partidos, candidatos e empresas. O problema ocorre quando agentes privados pretendem mais do que simplesmente traduzir suas preferências sobre políticas governamentais, buscando retorno futuro de seu investimento, sob a forma de rent-seeking, informações ou tratamento privilegiado em decisões sobre contratos ou regulação pública (Pinto-Duschinsky, 2002; Usaid, 2003; Bryan e Baer, 2005; Scarrow, 2006; Speck, 2006, Reis, 2008). Por outro lado, riscos eleitorais decorrentes de escândalos provocados por denúncias de corrupção reforçam demandas direcionadas para a oferta de subsídios públicos como fonte para a provisão de recursos financeiros destinados a dar suporte a campanhas eleitorais (Scarrow, 2007; Van Biezen, 2003; 2004). Observando democracias em funcionamento hoje no mundo, pode-se identificar pelo menos três modelos de subvenções oferecidos aos partidos, a partir de recursos públicos: (i) serviços e concessões estatais, como espaços gratuitos em rádio e televisão ou franquia de correios; (ii) apoio indireto, por meio de incentivos e isenções fiscais para financiadores privados; e (iii) fundos públicos destinados a subvenções diretas aos partidos (Katz, 1996). 
No que diz respeito a um dos recursos mais importantes na competição eleitoral, constituído pelo acesso aos meios de comunicação, pode-se observar variações em uma escala (Farrell, 1996), que vai de países que proíbem propaganda paga, permitindo exclusivamente o espaço público gratuito aos partidos (Brasil, Bélgica, Espanha, França, Holanda, Índia), aqueles que oferecem acesso a espaços públicos ao mesmo tempo que permitem propaganda paga (Austrália, Canadá, Japão, Suécia), até os casos de propaganda exclusivamente paga nos meios de comunicação (Estados Unidos, México).

Ainda que staff parlamentar, franquia postal e acesso a meios de comunicação sejam exemplos de recursos públicos postos à disposição de estruturas partidárias há mais tempo, a oferta de subsídios diretos sob a forma de fundos públicos empregados para a manutenção permanente de organizações partidárias e estruturas eleitorais ${ }^{1}$ constituem tendência mais recente, sobretudo dos últimos 25 anos, como resposta ao incremento nos custos de campanhas eleitorais e a exposição provocada pelo uso de dinheiro privado (Scarrow, 2006). Por outro lado, a dependência crescente dos partidos em relação à provisão de fundos públicos completa o ciclo de conversão dos sistemas partidários das poliarquias institucionalizadas em cartel-parties (Katz e Mair, 1994).

\section{TIPOS DE LEGISLAÇÃO DE FINANCIAMENTO ELEITORAL}

O declínio do grassroots partidário e a necessidade de fontes alternativas de financiamento (dinheiro privado e subsídios estatais) introduziram uma nova agenda de regulação sobre condições de acesso a recursos financeiros, limites para gastos eleitorais e exigências de transparência quanto à origem e uso de doações particulares. Levantamento realizado pelo International IDEA (Institute for Democracy and Electoral Assistence) identificou 84 nações que apresentam alguma legislação voltada a regular o financiamento de partidos e campanhas eleitorais. Previsivelmente, a maioria dos casos (59) corresponde a países classificados como free conforme ranking anual promovido pela Freedom House, embora pelo menos 26 nações classificadas como parcial ou não free também possuam legislação de controle sobre acesso ou utilização de recursos financeiros (IDEA, 2003).

A constituição de agência destinada a garantir o enforcement de regras e restrições está presente em 74 casos investigados pelo IDEA. Entre os exemplos mais significativos, pode ser apontada a Federal Election 
Commission americana, formada por três membros democratas e três republicanos, indicados pelo presidente após consulta aos líderes no Congresso, e submetidos à confirmação no Senado, para um mandato de seis anos. Suas atribuições correspondem a garantir as restrições, limites e disposições de publicização de informações fixadas na legislação específica. Já a Commission Nationale des Comptes de Campagne et des Financements Politiques francesa é formada por nove membros indicados pelo governo para um período de cinco anos, e destina-se a aprovar ou rejeitar relatórios partidários de gastos em campanhas eleitorais. No Reino Unido, a criação da Electoral Commission, agência voltada para o monitoramento e controle dos gastos eleitorais, data apenas de 2001. Seus membros são indicados pela rainha, após consultas ao primeiro-ministro e líderes da oposição, trabalham em tempo parcial por um período de cinco anos e está encarregada de registrar doações e regular gastos partidários (Nassmacher, 2003) .

Considerando o escopo da legislação destinada a regular o financiamento eleitoral, pode-se verificar uma variedade de dispositivos empregados (Anexo 1). O modelo mais frequente consiste na provisão de subsídios públicos destinados à manutenção de organizações partidárias e gastos de campanhas eleitorais. Subvenções estatais podem ser encontradas em 65 países, entre os quais poliarquias institucionalizadas (Reino Unido, Alemanha, França, Austrália, Dinamarca, Suécia, Holanda, Canadá), e nações da América Latina (Argentina, Brasil, Paraguai), África (Cabo Verde, Moçambique, Nigéria, África do Sul) e Leste europeu (Rússia, Polônia, Bósnia, Hungria), caracterizadas como poliarquias recentes ou quase-poliarquias. Em alguns casos (Bósnia-Herzegovina, Suíça), a provisão de subvenções estatais restringe-se a bancadas parlamentares. Em outros (Malauí, Tanzânia), dependem da disponibilidade de fundos constituídos por contribuições privadas (IDEA, 2003). Quanto ao período de cobertura das subvenções públicas, a maioria dos casos (38) permite o uso dos recursos, seja durante campanhas eleitorais ou nos intervalos entre eleições. A distribuição destes fundos públicos entre os partidos obedece predominantemente a um critério de performance eleitoral, traduzida em votos em eleições prévias (Alemanha, Dinamarca), correntes (Austrália, Canadá, Espanha, Uruguai), cadeiras legislativas (Áustria, Israel, Holanda, Reino Unido) ou, ainda, combinações de critérios, como na França, que utiliza votos com número de candidatos apresentados. A adoção de critério de distribuição igualitária dos recursos públicos entre partidos pode ser encontrada em doze países, entre os quais Rússia, Azerbaijão 
e Tailândia, além de outros que o combinam com desempenho eleitoral (Argentina, México).

Contrapartida à fixação de subsídios públicos pode ser verificada na introdução de regras determinando a publicização de contribuições privadas e do uso de recursos públicos e privados pelos partidos. Pelo menos 58 países impõem aos partidos a divulgação das doações recebidas, e 52, dos gastos executados. Cerca de duas em cada três nações que oferecem subvenções estatais às organizações partidárias exigem a apresentação pública da utilização destes recursos, restando 21 casos com legislação omissa a respeito. Finalmente, são menos frequentes legislações que fixam restrições mais rígidas, como limites máximos para a arrecadação de recursos privados, ou a proibição de contribuições privadas por empresas que exercem concessões ou contratos públicos. Argentina, Bélgica, Espanha, Estados Unidos, França, Israel, Itália, Rússia são casos exemplares de fixação de tetos máximos para contribuições. Interdição de doações por agentes que dispõem de contratos públicos pode ser verificada mais uma vez na Argentina, Espanha, Estados Unidos, França, Itália, como também Bulgária, México. No Japão, a restrição à contribuição limita-se ao período eleitoral (IDEA, 2003).

\section{EFEITOS DA LEGISLAÇÃO DE FINANCIAMENTO ELEITORAL SOBRE ÍNDICES DE CORRUPÇÃO}

Duas perguntas se apresentam a partir da observação das variações no escopo da regulação sobre financiamento de partidos e campanhas eleitorais: uma primeira indagação - que foge aos objetivos deste trabalho - diz respeito ao impacto do aumento de subsídios e financiamento público sobre a competição partidária. As respostas encontradas nos estudos eleitorais vão da ênfase atribuída à cartelização partidária (Katz e Mair, 1994; Mair, 1997) como decorrência do congelamento de sistemas partidários, provocado pela dependência de recursos públicos, distribuídos conforme votos obtidos em disputas eleitorais pretéritas, até conclusão oposta, de efeitos marginais exercidos pelo dinheiro público, salvo em circunstâncias em que valores e limiares de acesso sejam, ambos, elevados (Scarrow, 2006:625).

Mais saliente para os objetivos deste artigo é a pergunta a respeito da eficácia da legislação que regula o financiamento de campanhas eleitorais (doações privadas e subsídios públicos) em relação ao desempe- 
nho institucional e controle sobre corrupção nas instituições públicas. Entende-se por corrupção recompensa oferecida a funcionário público em troca de favorecimento ilícito em decisões sobre alocação de recursos públicos, como contratos, concessões, licitações, serviços, empréstimos, isenções, verbas ou informações. Assume-se a distinção proposta por Rose-Ackerman (1999), e Kunicová e Rose-Ackerman (2005), entre corrupção e pork-barrel: embora conexão eleitoral constitua uma transação entre eleitores e candidatos baseada na expectativa de troca de votos por distribuição concentrada de benefícios ou serviços, a fronteira que distingue corrupção de trocas clientelísticas pode ser identificada na (i) natureza competitiva ou monocrática da decisão executada por agente público; e (ii) na ilegalidade que caracteriza a transação corrupta: "pagamentos são corruptos se forem ilegalmente feitos a funcionários públicos com a intenção de obter um benefício ou evitar um custo" (Rose-Ackerman, 1999:9). Em outras palavras, não é ilegal que eleitores recompensem com votos candidatos que, acreditam, melhor representem seus interesses - vis à vis o interesse de outros eleitores - obtendo bens e serviços particularistas, a despeito das considerações sobre seus efeitos sobre a racionalidade na alocação de recursos públicos. Recompensar um agente público por uma decisão que de outra forma não seria tomada, ou que viola procedimentos legais de isonomia e universalismo, implica ultrapassar a linha divisória que demarca a corrupção de outras transações baseadas em reciprocidade específica ${ }^{2}$.

Pode-se afirmar que exista uma relação entre a presença de legislação para regulação do financiamento de campanhas eleitorais e maior transparência junto às instituições públicas? As nações que possuem regras de controle sobre contribuições e gastos eleitorais apresentam menos corrupção? Pode-se obter uma resposta quando comparamos os registros de legislação sobre financiamento eleitoral com indicadores sobre a importância da corrupção em cada nação. Embora a mensuração da corrupção constitua uma tarefa muito complexa, e sua realização mediante índices de percepção não esteja isenta de importantes vieses (Avritzer, 2008; Treisman, 2007; Power e Gonzalez, 2003; Bardham, 1997), relatórios como os produzidos anualmente pelo Banco Mundial e pela Transparency International, que conferem notas e classificam cerca de 170 países quanto à corrupção percebida por especialistas e consultores internacionais, permitem o exercício comparativo baseado em uma imagem aproximada sobre a presença diferenciada do fenômeno da corrupção no mundo. Dada a impossibilidade de mensurar e comparar um fenômeno como corrupção a partir da fre- 
quência de eventos (denúncias, punições), uma vez que estes são função de incentivos ou sanções oferecidas pelas regras institucionais, sua aferição por meio da percepção de consultores especializados permite uma proxy fiável. Por outro lado, não parece persuasivo invalidar um indicador simplesmente por este se basear em percepções, como se estas necessariamente fossem completamente enviesadas. Neste caso, percepções de usuários sobre qualidade dos serviços públicos, ou de cidadãos sobre desempenho governamental, deveriam ser, igualmente, descartadas sob argumento do viés que igualmente podem conter. Finalmente, com a cautela e prudência recomendáveis, a literatura dedicada a examinar comparativamente o fenômeno da corrupção tem empregado indicadores de percepção, da Transparency International ou World Bank, como Jackman e Montinola (2002), Idea (2003), Kunicová e Rose-Ackerman (2005), Bryan e Bauer (2005), Walecki (2005), Chang e Golden (2006), Treisman (2007), Kaufman, Kraay e Mastruzzi (2009).

A Transparency International (TI) atribui anualmente notas aos países, de 0 (corrupção extrema) a 1 (maior transparência). No Relatório de 2009,124 países foram classificados como tendo alta corrupção $(72,5 \%)$ e 47 (ou 27,5\%), baixa corrupção (Transparency, 2009).

Qual é o desempenho de nações que possuem legislação destinada a regular finanças eleitorais, quando consideradas as notas de corrupção/transparência conferidas pela Transparency International? Seria de se esperar que a existência de restrições à arrecadação de fundos pelos partidos, a obrigação de publicização de contribuições e gastos, disponibilidade de fundos públicos e/ou instituições destinadas a produzir o enforcement às regras apresentassem melhor desempenho no controle da corrupção, em relação aos demais países. Quando se considera nações classificadas pela TI como apresentando "baixa corrupção", o resultado parece confirmar que instituições (eleitorais) importam: dos 37 casos enquadrados nesta situação, pelo menos $32(86,5 \%)$ possuem leis restringindo arrecadação ou gasto de dinheiro em campanhas eleitorais. Contudo, dos 80 casos relacionados pelo IDEA como apresentando algum tipo de regulação para obtenção de dinheiro para campanhas eleitorais ${ }^{3}, 48$ (equivalente a $60 \%$ dos casos) obtiveram notas conferidas pela $T I$ inferiores a 5,0, correspondendo à classificação "alta corrupção". O padrão esperado - regulação eleitoral acompanhada por baixa corrupção - pode ser isolado em apenas 32 países (ou $40 \%$ dos casos). Como esta informação pode ser interpretada? 
Quando Leis Não Produzem os Resultados Esperados...

Tabela 1

Índice de percepção de corrupção $x$ países com legislação

de financiamento eleitoral

\begin{tabular}{l|c|c}
\hline \multicolumn{1}{c|}{ Legislação } & Não & Sim \\
Corrupção & \multicolumn{2}{c}{0} \\
\hline Alta Corrupção [CPI < 5.0] & \multicolumn{2}{c}{$0,431(0,512$ sig $)$} \\
\hline Baixa Corrupção [CPI >5.0] & \multicolumn{3}{|c}{0,067} \\
\hline$X^{2}$ & \multicolumn{3}{|c}{} \\
\hline V Cramer
\end{tabular}

Fonte: IDEA; Transparency International.

O valor do $x^{2}$ e do $\mathrm{V}$ de Cramer indicam que a relação entre legislação e desempenho relativo à percepção de corrupção não é significativa. Provavelmente seja convincente concluir que legislação eleitoral constitua condição necessária para restringir a corrupção nas instituições públicas (a grande maioria das nações com baixa corrupção possuem leis para controlar o dinheiro de campanhas eleitorais). Entretanto, estes mesmos dados sugerem que esta regulação represente condição insuficiente para assegurar transparência institucional: três em cada cinco países com legislação para regular a captação de dinheiro em campanhas eleitorais apresentam altos níveis de corrupção, segundo a Transparency International.

Neste ponto, o problema parece dirigir-se para a pergunta acerca de quais atributos distintivos permitem que - entre países que possuem legislação para controlar finanças eleitorais - alguns apresentem transparência institucional, enquanto outros mantenham altas taxas de corrupção.

Na observação prévia, a informação sobre a legislação de finanças eleitorais foi simplesmente agregada em um único registro dicotômico (possui/não possui), desconsiderando tanto a existência de diferentes tipos de regras destinadas a limitar contribuições e gastos, impor publicização do dinheiro arrecadado e executado pelos partidos, oferecer subvenções públicas ou, ainda, promover instituições destinadas a garantir a execução desta legislação, quanto a extensão da legislação, ou seja, o fato de uma determinada nação possuir uma legislação singela com poucos dispositivos - ou mais detalhada e ampla. Seria possível encontrar um efeito positivo da legislação sobre a transparência institucional, mais forte em algumas modalidades de regras do que em outras? Ou, ainda, uma cobertura mais ampla, promovida por legislação 
Gráfico 1

Transparência por tipo de legislação

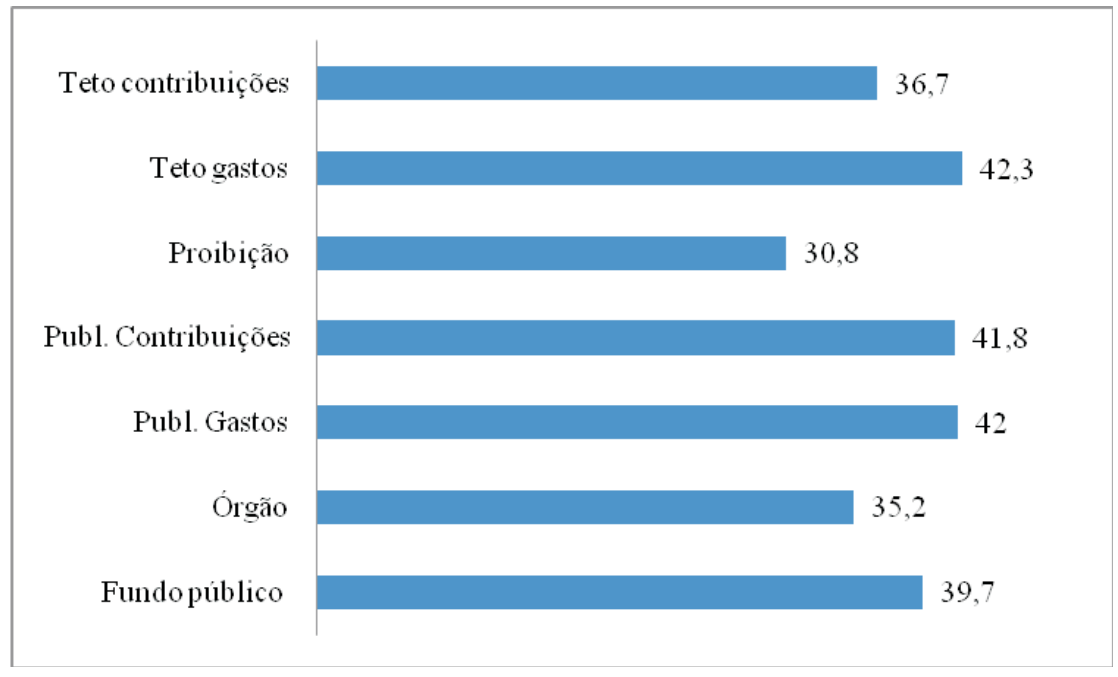

Fonte: IDEA.

com múltiplos dispositivos de controle seria mais eficaz do ponto de vista de restringir a presença de corrupção?

Desagregando a informação sobre o tipo de legislação existente em cada caso, e cotejando esta informação com a classificação promovida pela TI, revela-se um quadro pouco promissor acerca dos efeitos positivos gerados pelos dispositivos legais sobre o desempenho institucional. Para qualquer uma das restrições legais disponíveis à arrecadação e utilização de finanças em campanhas eleitorais, menos da metade dos casos em que pode ser encontrada esteve acompanhada por transparência e baixos níveis de corrupção. Seja restrições à arrecadação de recursos privados, imposição de publicização da origem e uso das contribuições, oferta de subvenções estatais ou órgão destinado a monitorar o cumprimento das regras, mostraram-se igualmente insuficientes para promover controle sobre corrupção nas instituições públicas.

Resta a dúvida sobre o efeito cumulativo produzido pela presença de múltiplos dispositivos legais para controlar finanças partidárias. Em outras palavras, faz diferença uma legislação singela ou mais extensa para a geração de transparência institucional? Países que apresentam a maioria, ou todos os dispositivos legais acima, têm mais probabilidade de controlar a corrupção do que aqueles com a presença limitada a um dispositivo? 
Quando Leis Não Produzem os Resultados Esperados...

Tabela 2

Relação entre número de dispositivos legislação financiamento eleitoral e status corrupção/transparência

\begin{tabular}{l|c|c|c}
\hline \multicolumn{1}{c|}{$\begin{array}{c}\text { Status } \\
\text { Dispositivos }\end{array}$} & Corrupção & Transparência & Total \\
\hline 1 a 4 & $\begin{array}{c}27 \\
(60 \%)\end{array}$ & $\begin{array}{c}18 \\
(40 \%)\end{array}$ & 45 \\
\hline 5 a 7 & 21 & 14 & 35 \\
\hline Total & $(60 \%)$ & $(40 \%)$ & $\mathbf{8 0}$ \\
\hline
\end{tabular}

Fonte: IDEA e Transparency International.

Independente da extensão e da cobertura da regulação legal sobre arrecadação financeira em campanhas eleitorais, parece não haver mudança no padrão predominante caracterizado por elevada corrupção institucional, mesmo em países com provisão legal de recursos de controle. Este paradoxo pode ser ilustrado pelos casos de Argentina, Benin, Bulgária, Equador, Itália e México, que, mesmo apresentando menu completo - limites para doações e gastos, publicização, fundos públicos e enforcement -, mantém elevados níveis de corrupção entre suas autoridades governamentais, conforme ranking gerado pela Transparency International.

\section{EM BUSCA DE EXPLICAÇÕES PARA A DISCREPÂNCIA}

Dos 80 países com legislação de controle sobre financiamento de campanhas eleitorais, 48 (equivalente a 60\%) apresentam índices elevados de percepção de corrupção, conforme medido pelo CPI da Transparency International. Isto permite concluir que na maioria dos casos nacionais que adotaram legislação sobre acesso a financiamento eleitoral, os níveis de transparência pública não foram alterados. A pergunta que se coloca a esta altura é a seguinte: por que alguns países que adotaram legislação sobre financiamento eleitoral apresentam transparência institucional, enquanto outros revelam elevados níveis de corrupção pública, apesar desta legislação?

Uma explicação para o efeito marginal exercido pela legislação sobre os níveis de corrupção poderia estar relacionada ao tempo de execução das regras em cada caso. Nesta perspectiva, resultados efetivos de con- 
trole sobre a arrecadação de dinheiro para campanhas deveriam ser verificados em casos de adoção longeva desta legislação, quando o tempo poderia exercer efeito de feedback positivo, exponenciando custos e riscos de estratégias rent-seeking, e induzindo comportamentos enquadrados aos marcos institucionais. Um problema, aqui, consiste em considerar as dificuldades de mensuração do intervalo temporal de aplicação desta legislação. A questão é que na maioria dos casos, a legislação presente de controle sobre finanças eleitorais não foi resultado de uma adoção em bloco, em uma única data do conjunto de dispositivos existentes em cada caso nacional. Ao contrário, teto para contribuições e gastos, proibição de doações de concessionários públicos, imposição de regras para publicização das finanças partidárias e fundos públicos foram implementados como respostas a diferentes desafios projetados sobre a competição eleitoral (Nassmacher, 2003). Mais ainda, a ordem dos fatores não é necessariamente a mesma, de forma que não basta isolar a data de adoção do primeiro dispositivo de controle e considerar o intervalo de operação até hoje.

Procedimento alternativo aqui adotado consistiu em isolar um dispositivo da legislação sobre finanças eleitorais e considerar sua data de adoção em cada caso nacional. Na sequência, cotejou-se a extensão do intervalo temporal com resultados efetivos em termos de transparência institucional, utilizando como proxy as notas da Transparency International. A data de introdução de fundos públicos para partidos e candidatos foi adotada como este marco de referência para considerar o efeito da legislação eleitoral. A justificativa para a escolha deste dispositivo baseia-se no impacto exercido pela oferta de subvenções públicas, seja sobre a competição eleitoral, como na provisão de recursos materiais para a profissionalização de campanhas eleitorais (PintoDuschinsky, 2002; Fogg, Molutsi e Tjernström, 2003; Van Biezen, 2003; Johnston, 2005; Zovatto, 2005; Scarrow, 2007; Roper, 2008). Em paralelo, parte dos modelos prescritivos voltados à produção de transparência institucional e neutralização de rent-seeking entre autoridades governamentais adota a presunção de que a disponibilidade de fundos públicos reduziria a dependência de partidos e candidatos em relação a doações privadas e, por consequência, à constituição de vínculos do tipo quid pro quo entre agentes públicos e interesses privados (Walecki, 2005).

O Uruguai foi pioneiro na introdução de fundos públicos para partidos, em 1928. Na sequência, Costa Rica (1949), Alemanha (1959) e 
Gráfico 2

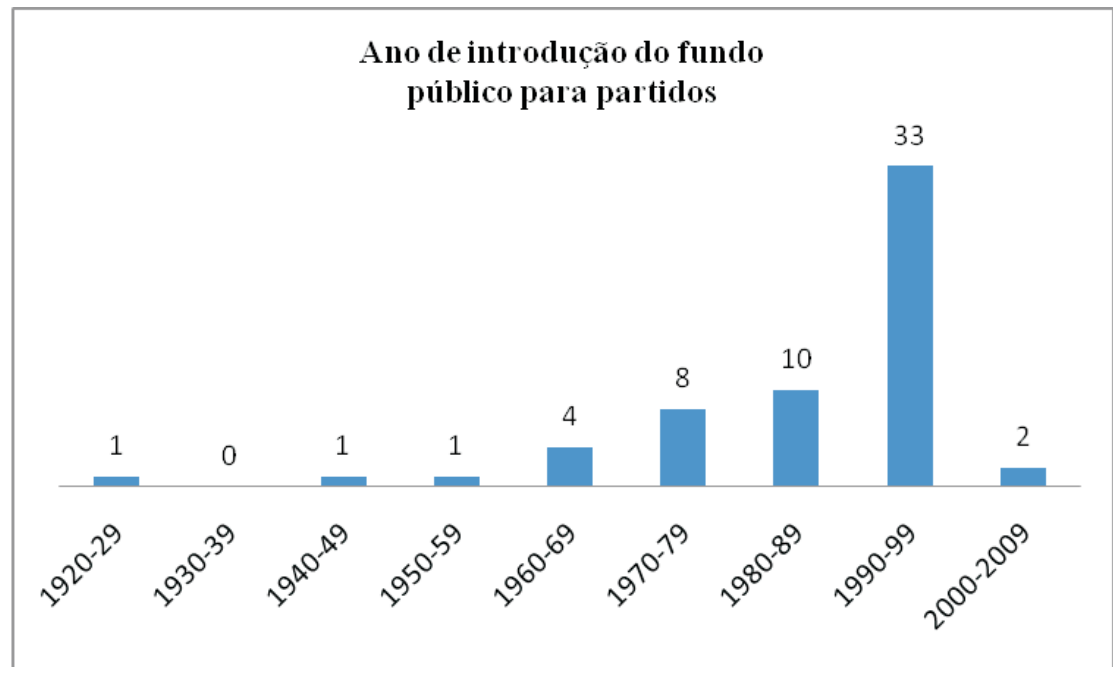

Fonte: IDEA; Database of Political Institutions; Democracy Cross-National Data.

Argentina (1961) produziram legislação criando subvenções estatais para organizações partidárias. Contudo, a primeira onda significativa nesta direção verifica-se somente a partir de 1970 (Noruega, Canadá, Itália e Espanha) e mais da metade dos países que atualmente contam com subsídios públicos promoveram este dispositivo após 1991, caso especialmente de novas democracias no Leste europeu e na África, mas também de poliarquias longevas, como Holanda e Reino Unido, que introduziram fundos partidários apenas em 1999. Chama a atenção que inexiste uma relação entre institucionalização ou estabilidade institucional e a ordem cronológica de adoção de fundos públicos: fenômenos complexos e tão distintos como declínio do ativismo partidário e ascensão dos cartel-parties nas velhas poliarquias, incremento de competição paralelo à visibilidade de estratégias rent-seeking, em novas poliarquias e regimes partly free, terminam por provocar uma convergência entre distintos padrões institucionais.

Em que medida o tempo de operação do financiamento público de campanhas eleitorais se converte em probabilidade de maior transparência e redução de percepção de corrupção pública? Extraindo as médias aritméticas para tempo de criação de fundos públicos, em países com alta (18,8 anos) ou baixa (28,2 anos) corrupção, sempre conforme classificação da Transparency International, verifica-se 9,6 anos a mais 
de operação de subvenções estatais em países com transparência institucional em relação àqueles com altas taxas de corrupção.

Tabela 3

Corrupção em relação a intervalo temporal adoção fundos públicos

\begin{tabular}{l|c|c}
\hline \multicolumn{1}{|c|}{ Tempo } & Curto $[\mathbf{t}<\mathbf{1 8}$ ] & Longo $[\mathbf{t}>\mathbf{1 8}]$ \\
Corrupção & 22 & 11 \\
\hline Alta Corrupção [CPI $<5.0]$ & 8 & 17 \\
\hline Baixa Corrupção [CPI $>5.0]$ & \multicolumn{2}{|c}{$6,85(0,009$ sig $)$} \\
\hline$X^{2}$ & \multicolumn{2}{|c}{0,344} \\
\hline V Cramer
\end{tabular}

Fonte: IDEA; Database of Political Institutions; Democracy Cross-National Data; Transparency International.

O V de Cramer indica que aproximadamente $12 \%$ da variação nas notas referentes à percepção de corrupção obtidas por países com legislação de financiamento eleitoral podem ser explicadas pelo intervalo temporal de funcionamento desta legislação, sugerindo uma relação, ainda que moderada, entre estas variáveis.

A diferença poderia estar relacionada à natureza do regime político, com maior eficiência da regulação de acesso a dinheiro em campanhas eleitorais em democracias, e combinação corrupção apesar da legislação em instituições não-poliárquicas? Os dados revelam que democracia provavelmente constitua condição necessária, mas não suficiente para assegurar efetividade à legislação gerada para regular finanças eleitorais. Das 32 nações que combinam legislação específica (IDEA, 2003) e bom desempenho relativo à transparência institucional (Transparency, 2009), nada menos do que 31 foram classificadas como free no relatório de 2009 da Freedom House. Paralelamente, de 25 casos que possuem legislação específica, mas não são democráticos (partly ou not free) não menos do que 23 apresentam alta percepção de corrupção, conforme a Transparency International. Contudo, dos 55 países que apresentam algum tipo de legislação de controle sobre dinheiro em campanhas eleitorais e apresentam bom prospecto em relação a liberdades civis e direitos políticos (Freedom House, 2009), 31 revelaram baixa percepção de corrupção, mas 24 nações (simultaneamente democráticas e com legislação regulatória) também apresentam elevada percepção de corrupção, entre estas, África do Sul, Argentina, Brasil, Índia, Itália, México. 
Quando Leis Não Produzem os Resultados Esperados...

Tabela 4

Relação entre corrupção e democracia

\begin{tabular}{|c|c|c|}
\hline $\begin{array}{ll} & \text { Corrupção } \\
\text { Democracia } & \end{array}$ & Alta & Baixa \\
\hline Free & 24 & 31 \\
\hline Partly + Not Free & 23 & 1 \\
\hline$x^{2}$ & \multicolumn{2}{|c|}{$19,636(0,000 \mathrm{sig})$} \\
\hline V Cramer & \multicolumn{2}{|c|}{0,495} \\
\hline
\end{tabular}

Fonte: Transparency International; Freedom House.

O valor do $x^{2}$ foi de 19,63, com uma probabilidade associada inferior a 0,001, sugerindo que a relação entre corrupção e democracia no grupo de países com legislação de financiamento eleitoral não resulta apenas de erro amostral. O V de Cramer encontrado foi de 0,49 , indicando que se pode explicar cerca de $24 \%$ da variação nas notas de corrupção dentro deste grupo a partir do status institucional (democracia ou não).

Democracias variam em seu desenho institucional, apresentando mais dispersão ou concentração em seus processos decisórios. Assim, o passo seguinte consiste em responder se determinada configuração institucional poliárquica poderia potencializar a eficácia da legislação de financiamento eleitoral em reduzir incentivos à corrupção.

De acordo com Kunicová e Rose-Ackerman (2005), espera-se que regras eleitorais e modelos constitucionais produzam efeitos significativos sobre oportunidades para a adoção de estratégias rent-seeking por autoridades públicas e, em consequência, sobre o desempenho institucional e níveis de corrupção. Políticos eleitos estariam submetidos a um trade-off entre incentivos para se apropriar de rendas não-legais no exercício de suas atividades (desvios, propinas) e a meta de se reeleger ou manter seu posto governamental em condições de monitoramento exercido por eleitores e opositores. Graus de competição e concorrência promovida pela oposição e monitoramento exercido pelos eleitores maximizariam riscos de punição eleitoral, inibindo apropriação destas rendas não legais por incumbents. Nesta direção, Kunicová e RoseAckerman (2005:585) indicam que sistemas eleitorais de maioria uninominal simples (plurality) ofereceriam incentivos fortes e habilidades para o monitoramento de incumbents por eleitores e concorrentes eleitorais. Além disto, diferente dos modelos de representação proporcional com lista fechada nos quais a liderança partidária concentra oportunidades de apropriação de rendas, distritos uninomiais produziri- 
am mais dispersão e divisão de recursos entre líderes e legisladores individuais. Por outro lado, eleição de representantes por plurality e por $\mathrm{RP}$ com listas abertas apresentariam em comum o vínculo entre eleitores e incumbents, potencializando monitoramento e punição. Contudo, maior visibilidade e potencial de responsabilização permitidos pela concentração da competição em dois ou poucos candidatos diferenciariam maioria uninominal simples da dispersão e maior custo de informação eleitoral em modelos de RP com lista aberta.

Além do procedimento para rankeamento de cadeiras partidárias, esforço relevante da literatura tem sido dirigido para estimar o efeito da magnitude eleitoral sobre as condições de monitoramento exercido por eleitores. Persson e Tabellini (2003) já haviam encontrado relação negativa entre magnitude eleitoral $(\mathrm{M})$ e corrupção: o incremento do número de vagas em disputa nos distritos eleitorais reduziria barreiras de entrada, ampliaria a competição eleitoral e, com isto, a informação disponível e o potencial de punição pelos eleitores. Mais recentemente, Carey (2009a; 2009b), formulou proposição em direção contrária: magnitudes eleitorais elevadas maximizariam os custos de monitoramento, ampliando a segurança de incumbents em combinar rent-seeking e manutenção de postos e carreira política. Sob voto proporcional de lista fechada, as posições superiores da ordem de candidatos são ocupadas por líderes partidários. Magnitudes elevadas permitiriam ampliar sua margem de segurança, mesmo face à perda de eleitores provocada por exposição partidária a escândalos ou denúncias (Carey, 2009b). Em paralelo, a combinação RP/lista aberta e M elevado igualmente representaria menor oferta de incentivos para monitoramento e punição, uma vez que sob esta configuração decrescem estímulos para a oferta de informação negativa por rivais e concorrentes eleitorais. Campanhas negativas reduziriam, sempre conforme Carey, custos de informação e ampliariam capacidades cognitivas dos eleitores, uma vez que disponibilizam conhecimentos retrospectivos sobre candidatos. O ponto, entretanto, seria que a vantagem de estratégias eleitorais direcionadas para informação negativa seria decrescente na medida em que aumente a dispersão de votos afetados por esta propaganda, $\mathrm{o}$ que deve ocorrer quanto maior o número de candidatos, em função da magnitude eleitoral de cada distrito. Em contraste, distritos de $\mathrm{M}$ pequeno ou próximo a 2, mudanças na direção do voto, provocadas por informação negativa, tendem a beneficiar o responsável por esta estratégia. 
Por outro lado Chang e Golden (2006) argumentam que magnitude eleitoral não produziria efeitos homogêneos, dependendo, para seus resultados, da interação provocada com as regras eleitorais de representação proporcional com listas abertas ou fechadas. A relação entre M e corrupção não seria linear, variando conforme as regras de designação de cadeiras legislativas: assim, deve-se esperar aumento da corrupção sob representação proporcional de lista aberta, combinada à elevada magnitude eleitoral $(M>15)$. Inversamente, voto proporcional em lista fechada e baixa magnitude $(\mathrm{M}<15)$ incrementa, igualmente, oportunidades para apropriação não legal de rendas. Ou seja, a estrutura de oportunidades mais favorável para corrupção pode ser tanto aquela em que voto nominal se combina ao incremento no número de candidatos provocado por M elevado (e consequente incremento no custo de informação eleitoral e menor capacidade de punição por eleitores), quanto em contextos nos quais a liderança partidária controla o processo de decisão sobre ordem dos candidatos nas listas partidárias e baixa magnitude implica maior quociente relativo, menor número de partidos e candidatos e, como resultado, menor competição eleitoral.

Também, a relação entre a estrutura do Poder Executivo e níveis de corrupção tem sido controversa no tratamento conferido pela agenda de estudos institucionais. Previamente, Myerson (1993) e Persson e Tabellini (2003) haviam encontrado relação inversa entre presidencialismo e corrupção, fundada, sobretudo, nos mecanismos de checks and balances gerados pela eleição separada de Executivo e Legislativo. Percorrendo caminho inverso, Kunicová e Rose-Ackerman (2005:587) indicam que a configuração institucional responsável por maximizar oportunidades de rent-seeking seria caracterizada pela combinação "presidencialismo + RP/lista fechada". Estas coordenadas promoveriam incentivos para uma aliança entre presidente e líderes partidários, dirigida para partilhar rendas com baixos custos de transação, marginalizando os rank-and-file e reduzindo capacidade de eleitores e opositores em monitorar autoridades governamentais.

O problema a ser resolvido, neste ponto, consiste em explicar por que alguns países que possuem legislação de regulação para o financiamento eleitoral revelam bom desempenho relativo à transparência institucional, enquanto outros continuam apresentando elevados índices de corrupção. Trata-se de encontrar atributos diferenciais entre os dois subgrupos que permitam isolar fatores que tornam eficaz a aplicação desta legislação de financiamento eleitoral. Para isto, executou-se uma 
regressão multivariada tendo por amostra o grupo de nações com algum tipo de dispositivo desta legislação, conforme o levantamento do IDEA. Dados acima ${ }^{4}$ (Tabela 2) mostraram ser irrelevante a diferença provocada pelo número de dispositivos que compõem a legislação, ou sua extensão. Desta forma, foram incorporados todos os casos nacionais com ao menos um tipo de dispositivo legal de regulação do financiamento eleitoral. Por fim, foram considerados países classificados como free, conforme classificação da Freedom House. Como variável dependente foram adotadas as notas conferidas pela Transparency International no Corruption Perception Index 2009, distribuídas entre 0 (maior corrupção) e 10 (menor corrupção, ou maior transparência).

Com a finalidade de considerar o efeito exercido por variáveis institucionais sobre a eficácia da legislação de financiamento eleitoral, foram adotadas as variáveis "magnitude eleitoral", e ainda, as dummy "presidencialismo" e "lista aberta", tendo por fontes o Database of Political Institutions ${ }^{5}$ e Democracy Cross-National Data ${ }^{6}$. Finalmente, foi empregada uma variável de controle, representada pelo "PIB per capita nacional", segundo valores de 2006, compilados pelo World Bank ${ }^{7}$. Os resultados são apresentados a seguir.

O modelo 1 testa a hipótese de Kunicová e Rose-Ackerman, sobre o efeito positivo provocado pelo first-past-the-post sobre baixas taxas de corrupção. Os resultados frustram esta expectativa, pois embora o sinal positivo do coeficiente beta indique que sistemas eleitorais uninominais de maioria simples sejam acompanhados por notas mais elevadas do CPI, a relação não é estatisticamente significativa, e os valores do coeficiente estão muito próximos a zero. O modelo 2 incorpora duas outras variáveis institucionais, "presidencialismo" e "lista aberta" e seus resultados mostram que quando controladas por indicadores de desenvolvimento econômico, os fatores institucionais elencados repetem coeficientes baixos e não significativos estatísticamente. O sinal do coeficiente beta para "presidencialismo" é negativo, indicando uma (pequena) relação entre governos presidenciais e maior corrupção. Paralelo, a "lista aberta" apresentou uma modesta associação positiva com o CPI, sugerindo mais probabilidade de valores elevados (menos corrupção) em regras eleitorais nas quais o eleitor ordena a lista de candidatos. O modelo 3 replica as variáveis institucionais anteriores, agregando "magnitude eleitoral", sempre controladas pela proxy para desenvolvimento econômico. Os resultados, contudo, não alteram os achados apresentados pelos modelos anteriores: PIB per capita conti- 
Quando Leis Não Produzem os Resultados Esperados...

Tabela 5

Índice de percepção de corrupção em países com legislação de financiamento eleitoral

\begin{tabular}{|c|c|c|c|c|c|c|}
\hline & Modelo 1 & Modelo 2 & Modelo 3 & Modelo 4 & Modelo 5 & Modelo 6 \\
\hline FPTP & $\begin{array}{l}0,003 \\
{[0,33]}\end{array}$ & - & - & $\begin{array}{l}0,062 \\
{[0,68]}\end{array}$ & - & - \\
\hline PRES & - & $\begin{array}{l}-0,084 \\
{[0,28]}\end{array}$ & $\begin{array}{l}-0,082 \\
{[0,29]}\end{array}$ & - & $\begin{array}{c}-0,396^{*} \\
{[0,60]}\end{array}$ & - \\
\hline LA & - & $\begin{array}{l}0,134 \\
{[0,27]}\end{array}$ & $\begin{array}{l}0,133 \\
{[0,28]}\end{array}$ & - & $\begin{array}{l}0,292 \\
{[0,60]}\end{array}$ & - \\
\hline M & - & - & $\begin{array}{l}0,011 \\
{[0,00]}\end{array}$ & - & $\begin{array}{l}-0,080 \\
{[0,06]} \\
\end{array}$ & - \\
\hline PIB & $\begin{array}{c}0,879 * * * \\
{[0,00]}\end{array}$ & $\begin{array}{c}0,855^{* * *} \\
{[0,00]}\end{array}$ & $\begin{array}{c}0,856^{* * *} \\
{[0,00]}\end{array}$ & - & - & $\begin{array}{c}0,906^{* * *} \\
{[0,00]}\end{array}$ \\
\hline $\mathrm{R}^{2}$ & 0,77 & 0,91 & 0,92 & 0,004 & 0,22 & 0,91 \\
\hline $\mathrm{R}^{2}$ adj & 0,77 & 0,83 & 0,84 & 0,009 & 0,18 & 0,83 \\
\hline $\mathrm{N}$ & 55 & 55 & 55 & 55 & 55 & 55 \\
\hline
\end{tabular}

Fonte: IDEA; Database of Political Institutions; Democracy Cross-National Data; World Bank; Transparency International.

Coeficiente $\beta$, sig e [erro-padrão] *** sig .000** sig .005

PIB = Produto Interno Bruto per capita, US\$ valores 2006 World Bank

FPTP = first-past-the-post, maioria simples em distritos uninominais

PRES = governo presidencialista

LA = representação proporcional com listas abertas

$\mathrm{M}=$ magnitude eleitoral

nua sendo a única variável estatisticamente significativa (com $1 \%$ de probabilidade de sua associação ser atribuída a erro amostral), enquanto atributos institucionais não parecem afetar as chances de um país que possua legislação de financiamento eleitoral ser mais ou menos corrupto. Na verdade, o ganho no $\mathrm{R}^{2}$ movendo-se do modelo 2 para o modelo 3 foi de apenas um ponto percentual.

Os modelos 4 e 5 consideraram apenas o efeito produzido por variáveis institucionais, desprezando-se a influência provocada por distintos níveis de desenvolvimento econômico, ou seja, considerando-se apenas as diferenças FPTP/outros, presidencialismo/governos nãopresidenciais, lista aberta / outros, e M, a despeito do status econômico de cada caso. Nesta situação, mais uma vez contrariando Kunicová e Rose-Ackerman, fórmulas eleitorais de maioria simples em distritos uninominais apresentaram associação residual e não estatisticamente 
significativa com níveis de corrupção percebida (modelo 4 ) e seu $\mathrm{R}^{2}$ indica capacidade de explicar apenas $4 \%$ da variação observada; presidencialismo mostrou-se significativo (a 5\%), com um coeficiente moderado e negativamente relacionado à transparência, ou seja, quando desprezadas as diferenças provocadas por níveis de desenvolvimento econômico, países com governo presidencialista apresentariam valores CPI em dois pontos inferiores ${ }^{8}$ (portanto, mais corrupção) aos de outros tipos de gabinetes; lista aberta e magnitude eleitoral não se mostraram significativos mesmo sob esta configuração, e a capacidade de previsão do modelo situa-se em apenas $22 \%$ (modelo 5).

Finalmente (modelo 6), quando são desprezadas as variáveis institucionais, fixando-se apenas no PIB per capita nacional, encontra-se uma fortíssima associação, significativa a $1 \%$ e capaz de explicar, com esta única variável, cerca de $91 \%$ da variação observada. A relação entre desenvolvimento econômico e redução da corrupção nas instituições públicas foi previamente observada pela literatura (Jackman e Montinola, 2002; Treisman, 2007). Consequências do desenvolvimento sobre bem-estar, como incremento nas taxas de renda, urbanização, escolarização e alfabetização, e seus efeitos sobre o custo de informação e monitoramento pelos cidadãos, no reforço de relações impessoais provocado pela expansão do mercado e da vida urbana e, finalmente, o aumento nos salários de funcionários públicos, com redução no valor marginal de rendas derivadas da corrupção, oferecem as conexões lógicas para a forte associação como a verificada no modelo 6. Único caso discrepante em relação à predição, com renda per capita superior a U\$ 10,9 mil e alta corrupção foi o da Itália. Em contraste, Chile, Uruguai, Costa Rica, Estônia, Lituânia, Hungria, Polônia e Ilhas Maurício apresentaram desempenho relativo superior ao projetado por seus respectivos PIB per capita. Traços institucionais comuns a estes oito casos podem ser identificados em número efetivo de partidos médio/alto $(5,1)$; em todos, o maior partido possui menos de $50 \%$ das cadeiras na Câmara baixa, e cinco possuem regra proporcional de voto preferencial ${ }^{9}$, atributos que minimizam a concentração decisória e podem contribuir para incentivar controles por grupos oposicionistas.

Estudos longitudinais como os de Treisman (2007) permitiram identificar a direção da causalidade como sendo desenvolvimento $=>$ transparência institucional, contestando proposições como as de North (1990), Mauro (1995), Rose-Ackerman (1999) ou mais recentemente, Clausen, Kraay e Nyiri (2009) para quem instituições marcadas por transparên- 
Gráfico 3

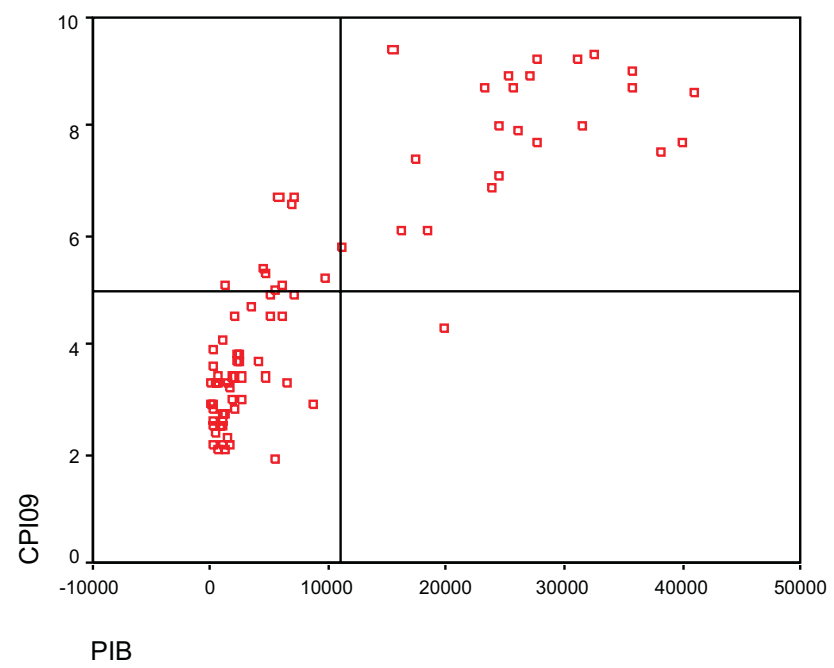

Fonte: IDEA; Transparency International.

cia e inóspitas a comportamentos rent-seeking de agentes governamentais incrementam níveis de confiança, incentivando investimentos.

\section{CONCLUSÃO}

Este trabalho pretendeu responder a uma pergunta: por que, mesmo adotando legislação destinada a regular a captação de recursos financeiros para campanhas eleitorais, alguns países não obtêm resultados satisfatórios em termos de redução ou eliminação de corrupção, mensurada por meio dos índices de percepção de corrupção, elaborados pela Transparency International?

Foi demonstrado que os resultados positivos não dependem do tipo ou extensão da legislação; que configuração institucional poliárquica constitui condição necessária, mas não suficiente; e que há uma relação moderada entre o tempo de adoção da legislação e melhor desempenho no controle sobre a corrupção. Na sequência, procurou-se colocar à prova algumas hipóteses indicadas pela literatura sobre efeitos provocados por diferentes estruturas institucionais sobre corrupção: presidencialismo, modelos de listas partidárias em eleições sob voto proporcional e magnitude eleitoral. Apenas presidencialismo apresentou relação estatisticamente significativa, e, mesmo assim, com coeficien- 
tes moderados e unicamente quando não controlada por níveis de desenvolvimento econômico.

Os resultados aqui expostos chocam-se contra a suposição de que corrupção institucional endêmica possa ser eliminada via engenharia institucional promovida por diferentes modelos de reforma política. Exemplo desta premissa pode ser encontrado na exposição de motivos do Projeto de Lei no 2.679, que pretendia promover uma reforma política no Brasil, e resume um dos principais argumentos em favor de reforma institucional que impusesse financiamento exclusivamente público em campanhas eleitorais: "o convívio entre financiamento público e privado é problemático porque não inibe a ação do poder econômico, razão pela qual optamos, neste projeto, pelo financiamento público exclusivo" (Comissão Especial de Reforma Política, 2003). Nesta perspectiva, esperava-se que a exclusividade de recursos públicos para financiar campanhas partidárias devesse neutralizar a influência do poder econômico na competição eleitoral, ou a cobrança por decisões futuras para o resgate do investimento feito em candidatos.

Os achados revelaram que a variável mais robusta para explicar resultados discrepantes de países que adotam legislação de financiamento eleitoral foi o desenvolvimento econômico, medido pela proxy PIB per capita. Como estes dados devem ser interpretados? Mais do que replicar que "instituições importam", talvez isto nos sugira uma agenda de pesquisas relacionada a descobrir sob que condições instituições importam, ou seja, são capazes de produzir os efeitos a elas atribuídos?

A questão consiste em responder o que faz com que um partido respeite limites para captação de recursos ou a obrigação em publicizar sua receita, em vez de esperar que estas restrições sejam impostas a seus concorrentes eleitorais, enquanto ele as viola, beneficiando-se duplamente? Provavelmente, a resposta passe pelos mecanismos de "patrulha policial" disponíveis às instituições públicas: dispositivos de monitoramento e fiscalização sobre as contas partidárias e de seus contribuintes, órgãos de regulação e controle, mecanismos de punição efetivos. Por outro lado, em contextos nos quais os custos para a manutenção de mecanismos de "patrulha policial" sejam muito elevados, reduzindo sua eficiência ou probabilidade de punição, deve-se esperar incentivos para estratégias free-rider orientadas para a violação das normas. Redução nos custos de "patrulha policial" pode ser obtida mediante uma combinação do emprego de "alarmes de incêndio", dispositi- 
vos alocados de modo disperso que permitam soar alarmes ao menor sinal de violações. Aqui, provavelmente possam ser localizadas as conexões entre eficiência de instituições de regulação à captação de recursos eleitorais e maior desenvolvimento econômico. É provável que sob condições de pluralismo social e econômico o incremento na concorrência entre agentes econômicos eleve os riscos para transações corruptas entre interesses privados e funcionários governamentais, uma vez que sempre haverá maior probabilidade de que interesses excluídos nestas negociações tenham incentivos para denunciá-los.

(Recebido para publicação em fevereiro de 2010)

(Reapresentado em setembro de 2010)

(Versão definitiva em outubro de 2010)

\section{NOTAS}

1. Fundos partidários são aqui tratados de forma indiferenciada, compreendendo subvenções anuais ordinárias conferidas às organizações partidárias, como recursos para financiar campanhas eleitorais.

2. Para uma cuidadosa discussão sobre conceitos de corrupção, ver Vieira (2008).

3. Andorra, Antígua e Barbuda, Látvia e San Marino, possuem legislação referente a finanças eleitorais, mas não receberam classificação pela TI quanto à corrupção e, por esta razão, não foram considerados.

4. http://www.transparency.org/policy_research/surveys_indices/cpi/2009

5. http://www.nsd.uib.no/macrodataguide/set.html?id=11\&sub=1

6. http://www.pippanorris.com/

7. http://go.worldbank.org/1SF48T40L0

8. Coeficiente não-estandardizado $\mathrm{B}=-2,005$.

9. Chile, Estônia, Lituânia, Polônia e Uruguai. 


\section{REFERÊNCIAS BIBLIOGRÁFICAS}

AVRITZER, Leonardo. (2008), “Índices de Percepção de Corrupção”, in Avritzer, Leonardo et alii (eds), Corrupção: Ensaios e Críticas. Belo Horizonte, UFMG.

BARDHAM, Pranab. (1997), "Corruption and Development: A Review of Issues". Journal of Economic Literature, no 35, pp. 1320-1346.

BARTOLINI, Stefano. (2000), The Political Mobilization of the European Left, 1860-1980: The Class Cleavage. Cambridge, Cambridge University Press.

BRYAN, Shari e BAER, Denise. (2005), Money in Politics: A Study of Party Financing Practices in 22 Countries. National Democratic Institute for International Affairs. Washington DC.

CAREY, John. (2009a), Legislative Voting and Accountability. Cambridge, Cambridge University Press.

. (2009b), “Ingeniería Electoral: Qué nos Muestran las Investigaciones Académicas sobre los Efectos Anticipados de las Reformas Electorales?", in Fontaine, Arturo; Larroulet, Cristian; Navarrete, Jorge e Walker, Ignacio [orgs.], Reforma del Sistema Electoral Chileno. Santiago, PNUD, pp. 233-244.

CHANG, Eric e GOLDEN, Miriam. (2006), “Electoral Systems, District Magnitude and Corruption". British Journal of Political Science, no 37, pp.115-137.

CLAUSEN, Bianca; KRAAY, Art e NYIRI, Zsolt. "Corruption and Confidence in Public Institutions: Evidence from a Global Survey". The World Bank, Policy Research Working Paper Series no 5.157.

DE VREESE, Claes. (2009), “Campaign Communication and Media”, in Le Duc, Lawrence; Niemi, Richard e Norris, Pippa (eds.), Comparing Democracies. 3a ed. Londres, Sage Publications, pp.118-140.

FARRELL, David. (1996), “Campaing Strategies and Tactics”, in Le Duc, Lawrence; Niemi, Richard e Norris, Pippa (eds.), Comparing Democracies. Londres, Sage Publications, pp. 160-183.

FOGG, Karen; MOLUTSI, Patrick e TJERNSTRÖM, Maja. (2003), “Conclusion”, in IDEA, Funding of Political Parties and Elections Campaigns. Estocolmo, International Idea.

IDEA. (2003), Funding of Political Parties and Elections Campaigns. Estocolmo, International Idea.

JACKMAN, R. e MONTINOLA, G. (2002), "Sources of Corruption : A Cross-Country Study". British Journal of Political Science, Colchester, vol. 32, no 1, pp.147-170.

JOHNSTON, Michael. (2005), Political Parties and Democracy in Theoretical and Practical Perspectives. Political Finance Policy, Parties and Democratic Development. National Democratic Institute for International Affairs, Washington DC.

KATZ, Richard. (1996), "Party Organizations and Finance", in Le Duc, Lawrence; Niemi, Richard e Norris, Pippa (eds.), Comparing Democracies. Londres, Sage Publications, pp. 107-133.

e MAIR, Peter. (1994), How Parties Organize: Change and Adaptation in Party Organizations in Western Democracies. Londres, Sage Publications. 
KAUFMANN, Daniel; KRAAY, Aart e MASTRUZZI, Massimo. (2009), Governance Matters VIII: Aggregate and Individual Governance Indicators, 1996-2008. World Bank, Policy Research Working Paper, no 4978.

KUNICOVÁ, Jana e ROSE-ACKERMAN, Susan. (2005), “Electoral Rules and Constitutional Structures as Constraints on Corruption". British Journal of Political Science, no 35, pp. 573-606.

MAIR, Peter (1997). Party System Change: Approaches and Interpretations. Oxford, Oxford University Press.

e VAN BIEZEN, Ingrid. (2001), “Party Membership in Twenty European Democracies, 1980-2000". Party Politics, vol. 7, no 1, pp. 5-21.

MANIN, Bernard. (1995), Principes du Gouvernement Représentatif. Paris, Calmann-Levy.

MAURO, Paolo. (1995), "Corruption and Growth". Quarterly Journal of Economics, vol. 106, no 2, pp. 681-711.

MCCUBBINS, M. D. e SCHWARTZ, T. (1984), “Congressional Oversight Overlooked: Police Patrol versus Fire Alarm". American Journal of Political Science, no 28, pp. 165-79.

MYERSON, Roger. (1993), “Effectiveness of Electoral Systems for Reducing Government Corruption: A Game Theoretic Analysis". Games and Economic Behavior, no 5, pp.118-132.

NASSMACHER, Karl-Heinz. (2003), “Monitoring, Control and Enforcement of Political Finance Regulation", in IDEA, Funding of Political Parties and Elections Campaigns. Estocolmo, International Idea.

NORRIS, Pippa. (2000), A Virtuous Circle? Political Communications in Post-Industrial Democracies. Cambridge, Cambridge University Press.

PERSSON, Torsten e TABELLINI, Guido. (2003), The Economic Effects of Constitutions. Boston, MIT Press.

PINTO-DUSCHINSKY, Michael. (2002), “Financing Politics: A Global View”. Journal of Democracy, vol. 13, no 4, pp. 69-86.

POWER, Timothy e GONZALEZ, Julio. (2003), “Cultura Política, Capital Social e Percepções sobre Corrupção: Uma Investigação Quantitativa em Nível Mundial. Revista de Sociologia e Política, no 21, Curitiba, pp. 51-69.

REIS, Bruno P. W. (2008), “Sistema Eleitoral e Financiamento de Campanhas no Brasil: Desventuras do Poder Legislativo sob um Hiperpresidencialismo Consociativo", in Oliven, Ruben George; Ridenti, Marcelo Ridenti e Brandão, Gildo Marçal (orgs.), A Constituição de 1988 na Vida Brasileira. São Paulo, Aderaldo \& Rothschild Editores/Anpocs.

ROPER, Steven. (2008), “Introduction: The Influence of Public Finance on Post-Communist Party Systems", in Roper, Steven e Ikstens, Janis (eds.), Public Finance and Post-Communist Party Development. Londres, Ashgate.

ROSE-ACKERMAN, Susan. (1999), Corruption and Government: Causes, Consequences, and Reform. Cambridge, Cambridge University Press. 
SCARROW, Susan. (2006), "Party Subsidies and the Freezing of Party Competition: Do Cartel Mechanisms Work?". West European Politics, vol. 29, no 4, pp. 619-639.

. (2007), "Political Finance in Comparative Perspective". Annual Review of Political Science, no 10, pp. 363-390.

SPECK, Bruno. (2006), “O Financiamento de Campanhas Eleitorais”, in Avritzer, Leonardo e Anastasia, Fátima (eds.), Reforma Política no Brasil. Belo Horizonte, PNUD/UFMG.

TRANSPARENCY. (2009), Corruptions Perceptions Index 2009. http:/ / www.transparency.org/policy_research/surveys_indices/cpi/2009.

TREISMAN, Daniel. (2007), "What Have We Learned about the Causes of Corruption from Ten Years of Cross-national Empirical Research?". Annual Review of Political Science, vol. 10, pp. 211-244.

USAID. (2003), Money in Politics Handbook: A Guide to Increasing Transparency in Emerging Democracies. Office of Democracy and Governance, Washington DC.

VAN BIEZEN, Ingrid. (2003), Financing Political Parties and Electoral Campaigns: Guidelines. Estrasburgo, Council of Europe Publishing. . (2004), “Political Parties as Public Utilities”. Party Politics, vol. 10, No. 6, 701-722.

VIEIRA, James. (2008), Os Microfundamentos da Transação Corrupta: O Referencial Analítico da Corrupção Reconsiderado. Porto Alegre, Dissertação de Mestrado em Ciência Política, Programa de Pós-Graduação em Ciência Política, Universidade Federal do Rio Grande do Sul.

WALECKI, Marcin. (2005), Political money and corruption. IFES.

ZOVATTO, Daniel. (2005), “The Legal and Practical Characteristics of the Funding of Political Parties and Electoral Campaigns in Latin America", in IDEA, Funding of political parties and elections campaigns. Estocolmo, International Idea. 
Quando Leis Não Produzem os Resultados Esperados...

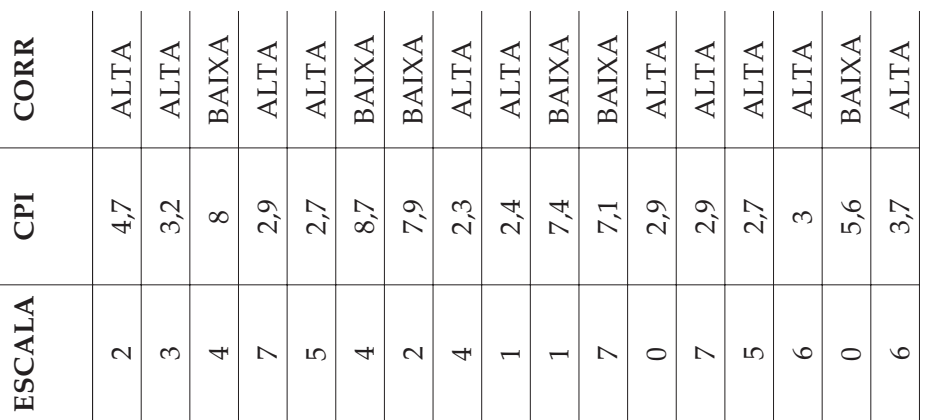

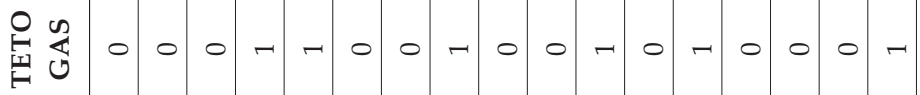

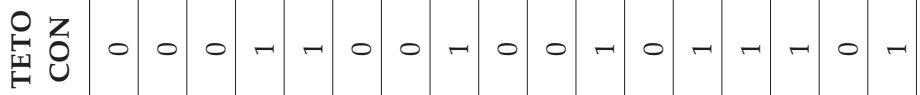

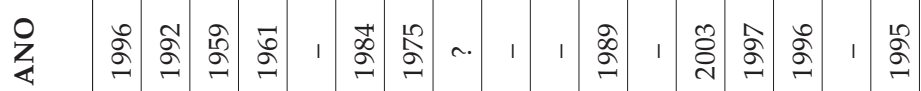

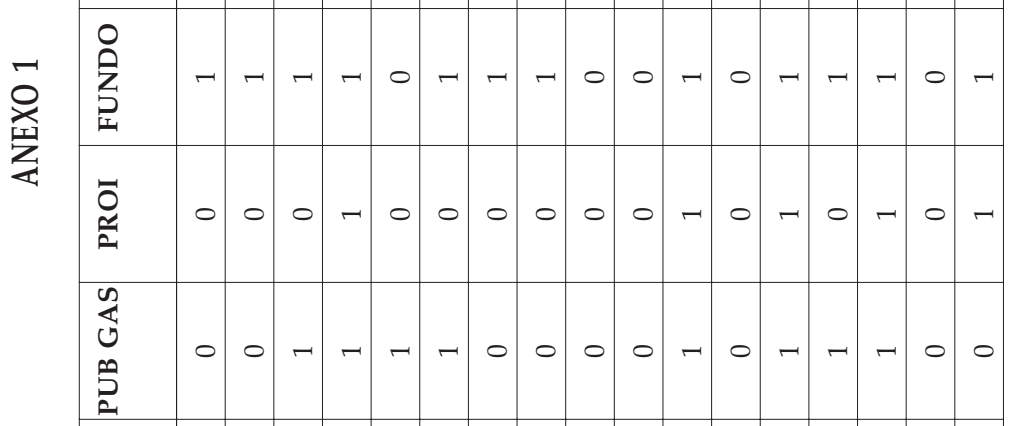

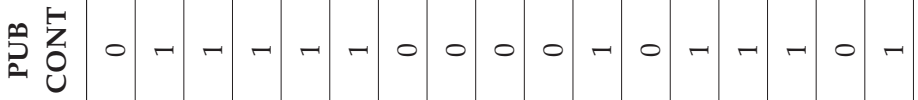

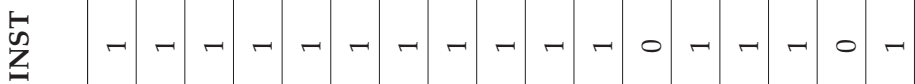

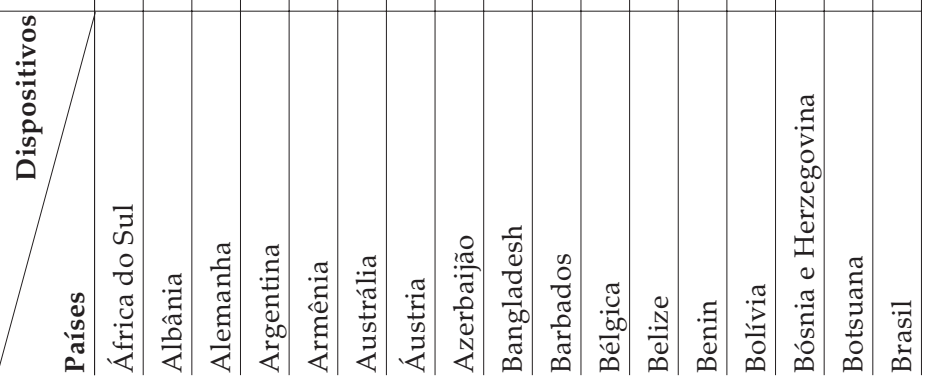


André Marenco

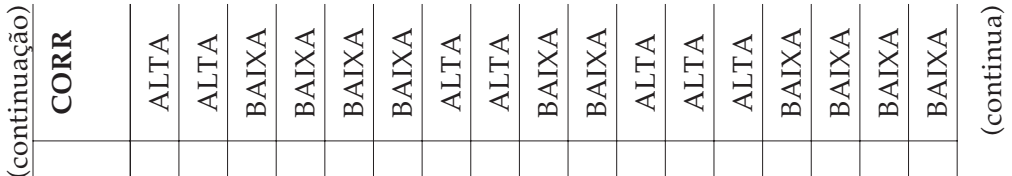

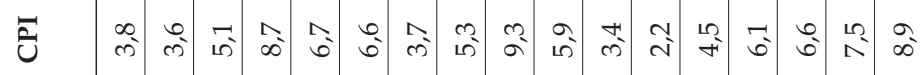

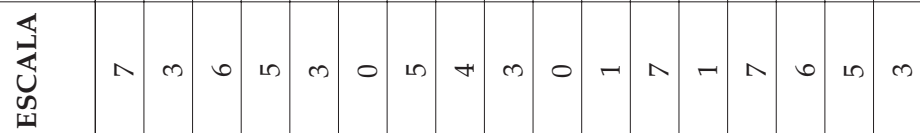

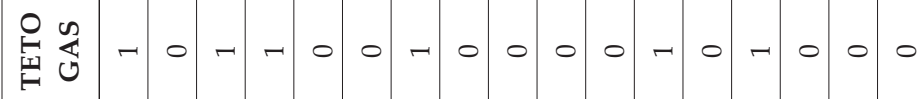

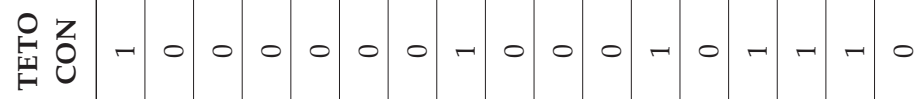

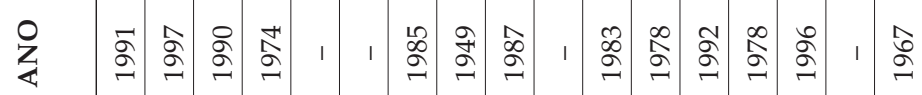

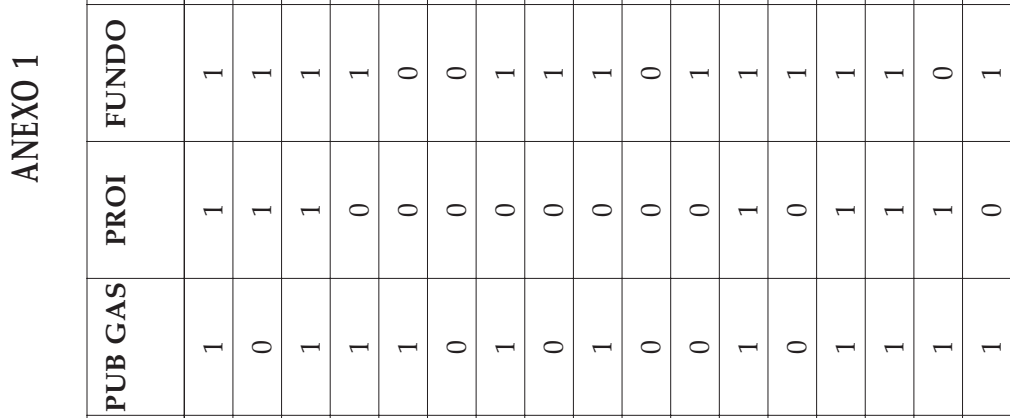

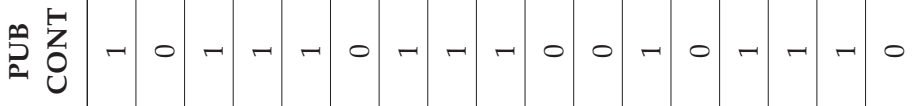

$$
\begin{aligned}
& \text { 占 }
\end{aligned}
$$

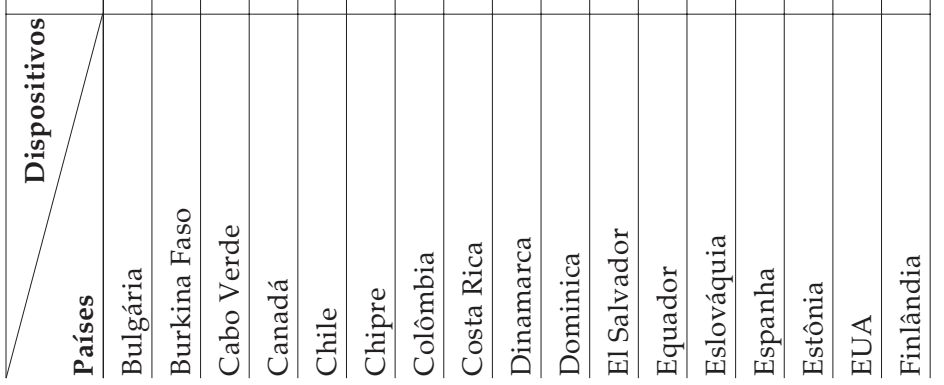


Quando Leis Não Produzem os Resultados Esperados...

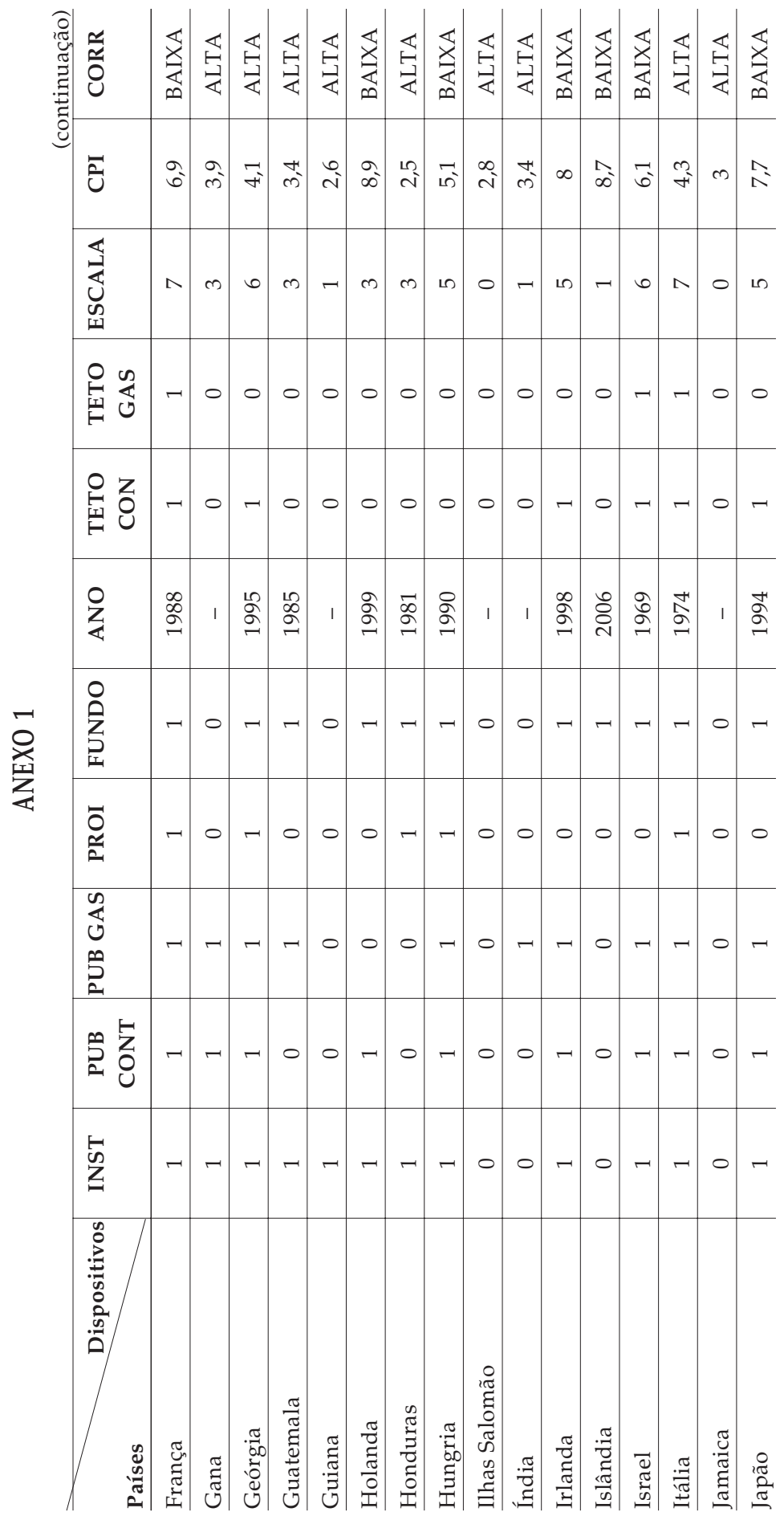


André Marenco

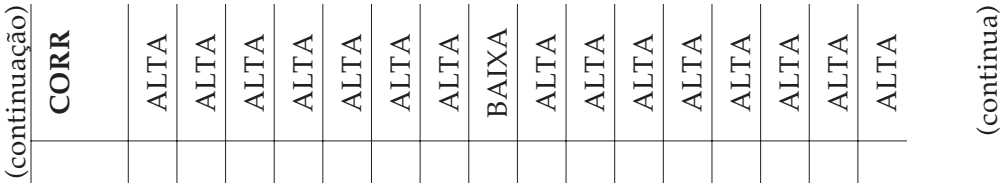

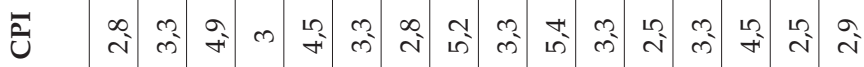

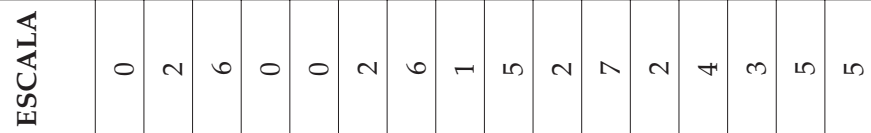

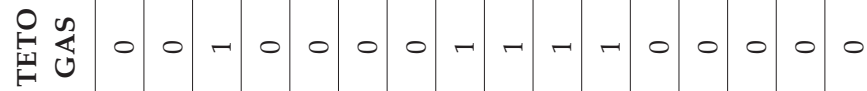

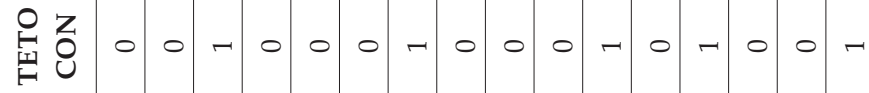

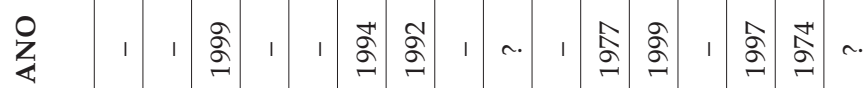

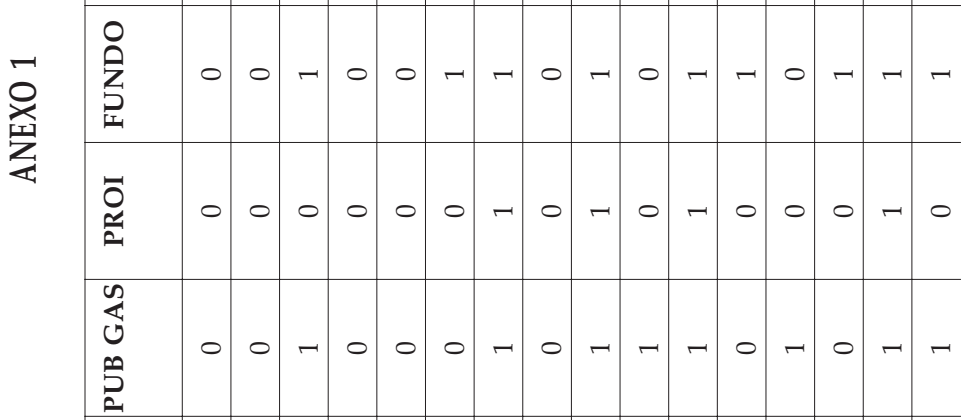

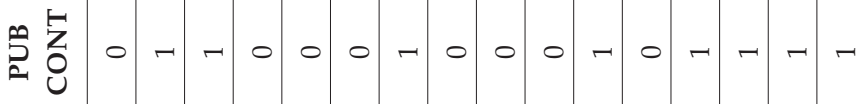

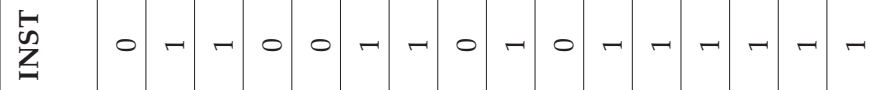

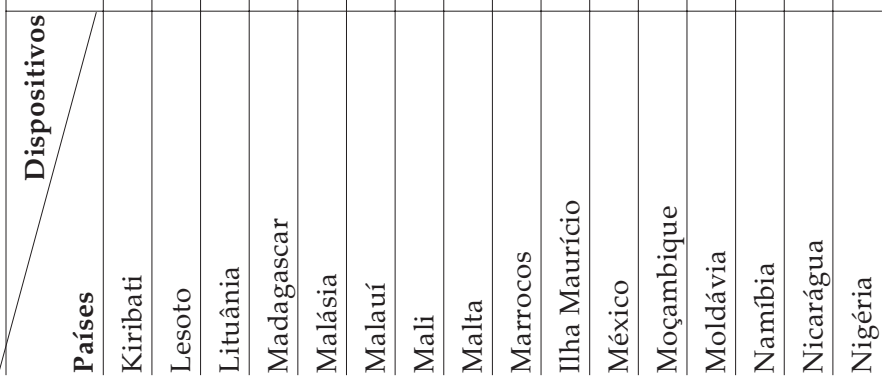


Quando Leis Não Produzem os Resultados Esperados...

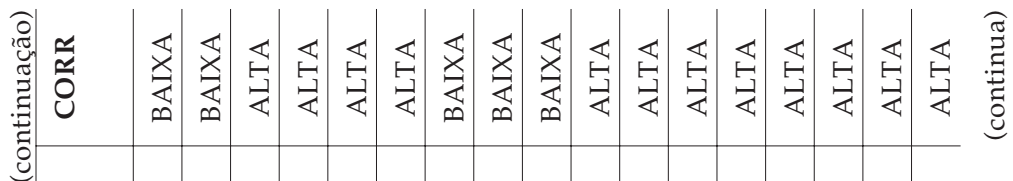

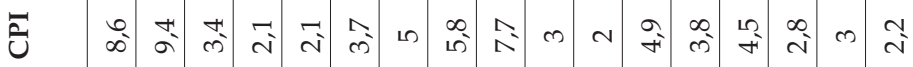

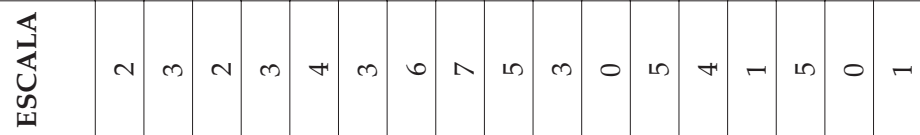

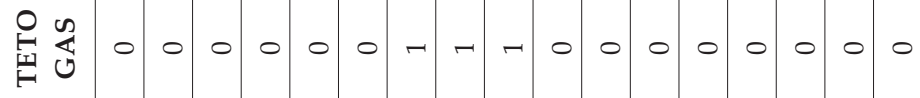

$\begin{array}{llllllllllllllllllllllll}0 & \text { Z } & 0 & 0 & 0 & 0 & 0 & 0 & 0 & -H & - & 0 & 0 & 0 & 0 & - & 0 & 0 & 0 & 0\end{array}$

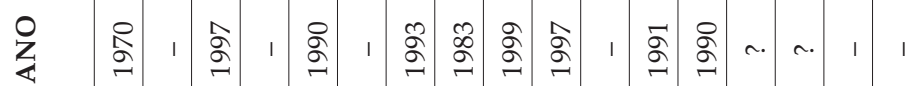

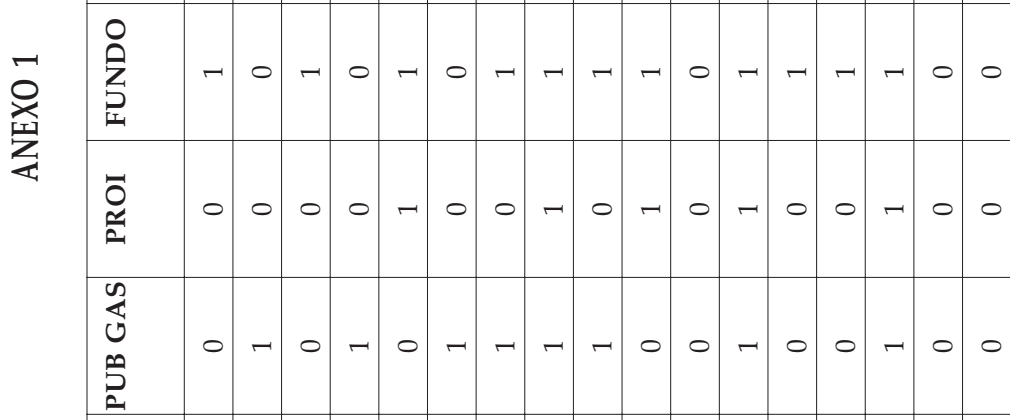

完完

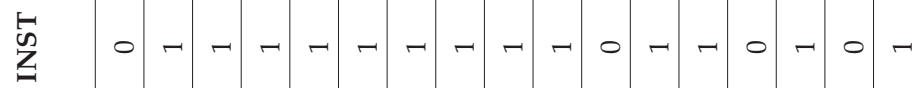

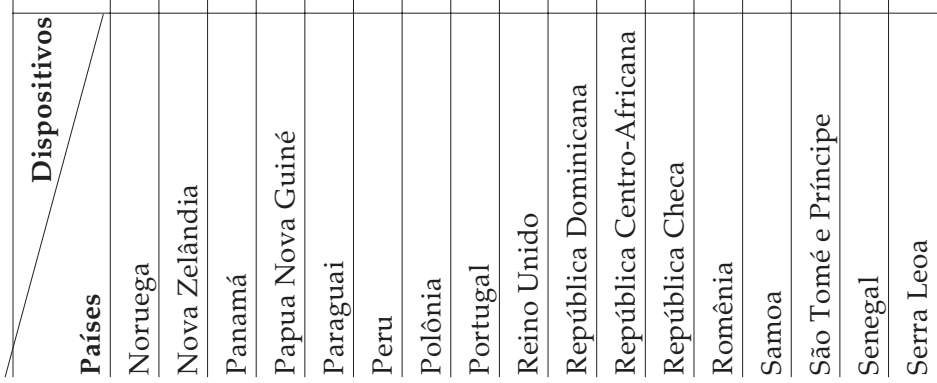


André Marenco

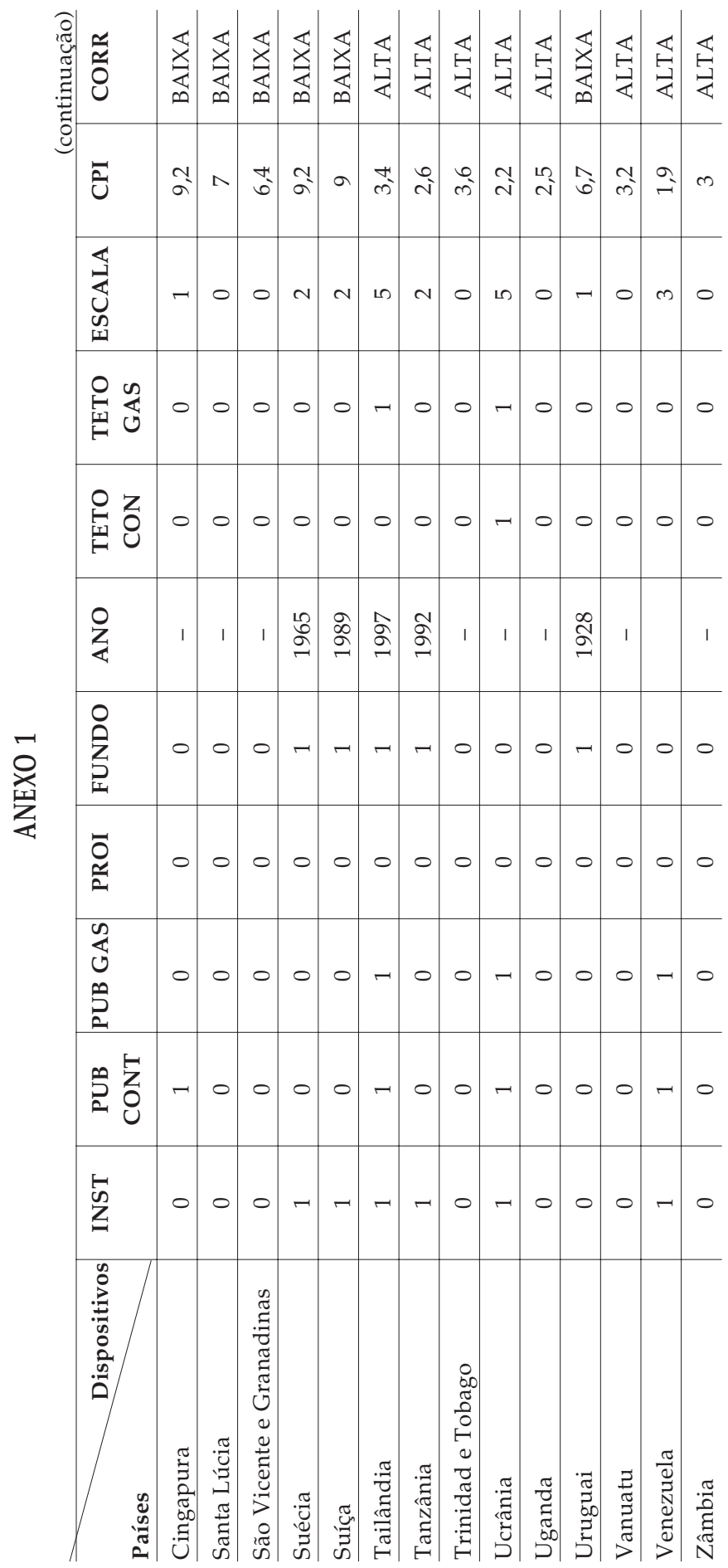




\begin{abstract}
When Laws Fail to Produce the Expected Results: Election Finance from a Comparative Perspective

Democracies have adopted different legislative models to regulate election finance: maximum limits to contributions, bans on donations by companies that provide public services or operate government concessions, and disclosure of private donations and public funds to cover campaign expenditures. The current study's underlying hypothesis is that there is no association between the legislation's rigor and improvement in indicators of institutional transparency. The study analyzes the extent to which different types of institutional formats like democracy, presidentialism, type of electoral slate, and size of voting districts, as well as economic development variables, can explain the failure of electoral legislation to produce transparency in election finance.
\end{abstract}

Key words: electoral legislation; election finance; transparency

\title{
RÉSUMÉ \\ Quand les Lois ne Produisent pas les Résultats Attendus: Financement Électoral dans une Perspective de Comparaison
}

Les démocraties ont adopté différents modèles de législation afin de régler le financement des campagnes électorales: plafonnement des contributions, dons interdits d'entreprises prestataires de services ou bénéficiaires de concessions publiques, publicité de donations privées et de fonds publics en règlement de frais électoraux. L'hypothèse qui guide cet article suggère une absence de rapport entre une législation rigoureuse et une amélioration des indicateurs de transparence institutionnelle. On y examine dans quelle mesure différents types de configurations institutionnelles telles que démocratie, régime présidentiel, type de listes électorales et étendue des districts électoraux, ainsi que des variables de développement économique, peuvent rendre compte de l'échec d'une législation électorale qui cherche à garder sa transparence.

Mots-clés: législation électorale; financement électoral; transparence 